\title{
Evidence against the structural gene encoding type II collagen (COL2A1) as the mutant locus in achondroplasia
}

\author{
DONALD OGILVIE*, PAUL WORDSWORTH*, ELIZABETH THOMPSON†, \\ AND BRYAN SYKES* \\ From * the Nuffield Department of Pathology, University of Oxford, John Radcliffe Hospital, Oxford OX3 \\ 9DU; and the Institute of Child Health, 30 Guilford Street, London WC1N $1 E H$.
}

SUMMARY The structure of the locus encoding the major cartilage collagen gene (COL2A1) was studied in a total of 19 cases of achondroplasia. No gross rearrangements were seen. The segregation of COL2A1 was examined in three affected kindreds using restriction site and length variants as genetic markers. In two kindreds discordant segregation between the achondroplasia and COL2A1 loci was demonstrated. Paternity/maternity was confirmed using a 'minisatellite' core sequence probe which reveals cross hybridising polymorphic loci.

Achondroplasia, the most familiar of the chondrodystrophies, is a well defined clinical entity inherited as a fully penetrant autosomal dominant trait. The incidence at birth is about 1:30000 and the mutation rate has been estimated at $14 \pm 5$ per million gametes with a paternal age effect. ${ }^{12}$ About $80 \%$ of cases are the result of new mutation and the prevalence is stabilised by selective elimination from the population due to a corresponding reduction in biological fitness. ${ }^{3}$

The characteristics of achondroplasia are rhizomelic dwarfism, bulging cranium, low nasal bridge, pronounced lumbar lordosis with a thoracolumbar gibbus, and caudal narrowing of the lumbar spinal canal. Biopsy of the chondro-osseous junction demonstrates regular and well organised endochondral ossification although this is often accompanied by an overgrowth of ossified periosteum. The relatively normal cellular architecture of the region has led to the suggestion that the basic defect in achondroplasia is a quantitative reduction in cartilage proliferation at the epiphyseal plate. ${ }^{4}$ The hormonal regulators of epiphyseal growth, growth hormone and somatomedin, have been shown to function normally in achondroplasia ${ }^{5}$ and recent attention has focused on disturbances of matrix synthesis.

Type II collagen is the major protein of the cartilage matrix and in man its subunit $\alpha$ chains are

Received for publication 3 June 1985

Revised version accepted for publication 27 June 1985 encoded at a single locus (COL2A1) on chromosome $12 .{ }^{6}$ The few biochemical studies that have been reported in achondroplasia have not revealed any abnormality of type II collagen content, extractability, or cyanogen bromide fragmentation pattern. ${ }^{7-9}$ Mutation of collagen structural genes can affect extracellular matrix synthesis and two reports, from the same laboratory, have associated changes in COL2A1 with achondroplasia. ${ }^{10}{ }^{11}$ In one patient the disorder was attributed to an insertion into COL2A1. In eight other cases large deletions at the same locus were inferred from gene dosage analysis.

Here we describe structural and segregation analyses to test COL2A1 as the achondroplasia locus.

\section{Patients and methods}

We studied 19 Caucasian patients with typical achondroplasia, of whom 15 had no previous family history. All were examined by at least one of the authors and all demonstrated the distinctive achondroplasia phenotype.

Extraction of DNA from peripheral blood, restriction enzyme digestion, electrophoresis, blotting, and hybridisation followed our usual versions of standard procedures. Gross rearrangements, that is, insertions or deletions of greater than about $100 \mathrm{bp}$, were screened with combinations of the restriction endonucleases Bam HI, EcoRI, HindIII, and PvuII. Segregation analysis used two types of variation found at this locus: (1) restriction site dimorphisms 


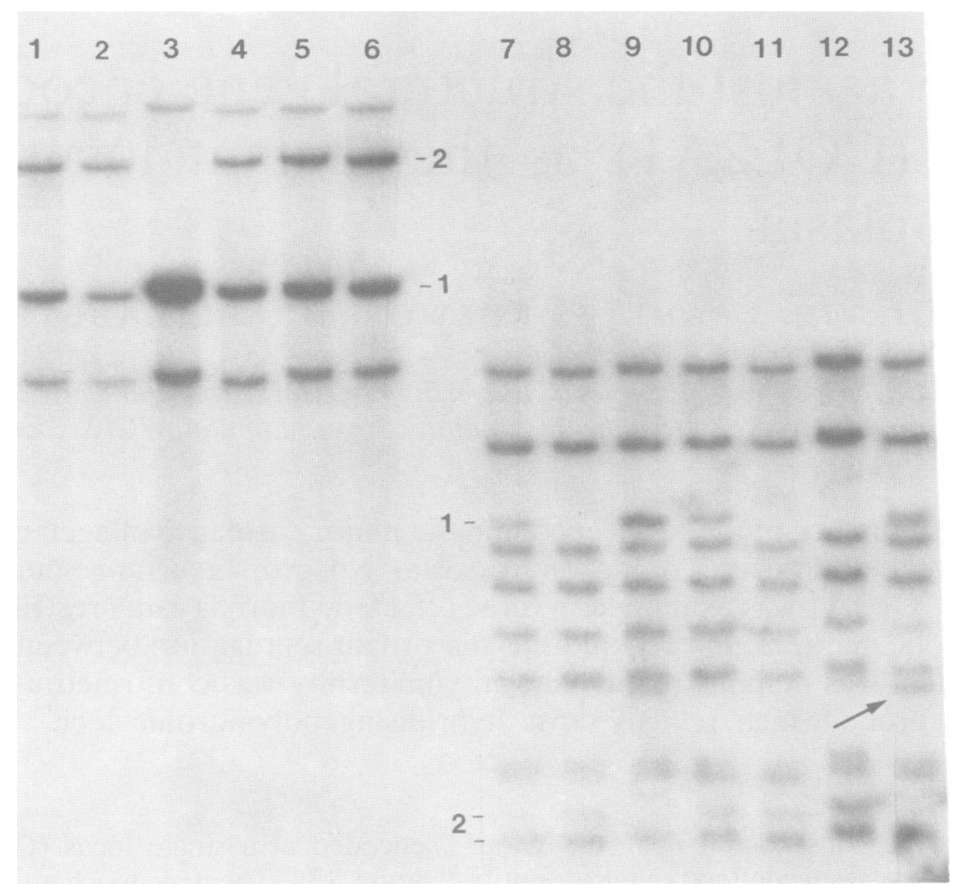

FIG 1 Restriction site and length variation at COL2A1: DNA from achondroplasia patients and their relatives digested with HindIII (tracks 1 to 6) and Pvull (tracks 7 to 13) and probed with cos H col 1 . A $14 \mathrm{~kb}$ HindIII fragment (allele 2) is cleaved at the variable site to give two comigrating $7 \mathrm{~kb}$ fragments (allele 1 ). Track 3 is an $\mathrm{H} 1-1$ homozygote, the others are $\mathrm{H} 1-2$ heterozygotes. A $3 \cdot 3 \mathrm{~kb}$ Pvull fragment (allele 1) is cleaved at the variable site to give two fragments at 1.6 and $1.7 \mathrm{~kb}$ (allele 2). Tracks 8, 11, and 12 are P 2-2 homozygotes, track 9 is a P 1-1 homozygote, and tracks 7, 10, and 13 are P 1-2 heterozygotes. Length variation beyond the $3^{\prime}$ end of the gene is seen in track 13, an unaffected subject who is homozygous for an allele (L2) (arrowed) which is about 100 to 150 bp shorter than the major allele (L1). The L1 fragment comigrates with a non-variable Pvull fragment. Tracks 7, 9, and 12 are L 1-2 heterozygotes and the others are L $1-1$ homozygotes. The identity of these variable length fragments was confirmed by rehybridising the blot with fragment E7 alone.

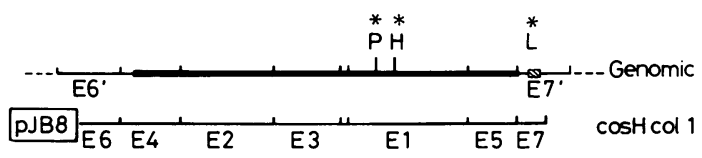

FIG 2 Location of the PvulI $(P)$ and HindIII $(H)$ restriction site dimorphisms and the E7' length polymorphism ( $L$ ) on the map of COL2Al (upper line). The coding region is indicated by the thicker line. The EcoRI map of the hybridisation probe cos H col I is shown on the lower line.

revealed by HindIII (H) and PvuII (P) ${ }^{12}{ }^{13}$; and (2) length polymorphism in a segment of DNA 1 to $2 \mathrm{~kb}$ downstream from the $3^{\prime}$ end of the gene. ${ }^{14} 15$ Paternity/maternity was tested using a 'minisatellite' core sequence as a hybridisation probe for Hinf $\mathrm{I}$ digests of DNA. ${ }^{16}$

\section{Results}

Fig 1 shows the three markers used in this analysis and fig 2 shows their location on the gene map. From this and other autoradiographs we were unable to detect any gross rearrangement of type II collagen gene structure that could not be accounted for by normal variation. The hybridisation probe cosH col 1 spans the $30 \mathrm{~kb}$ gene and $7 \mathrm{~kb}$ of flanking sequences. ${ }^{1718}$ Deletion of the entire gene from one chromosome could be discounted in 14 patients because they were heterozygous for at least one marker. The proportion (five of 19) of apparent homozygotes, who could conceivably be hemizygous at this locus, was within normal expectations.

Segregation analysis demonstrated discordant segregation of COL2A1 and the achondroplasia locus in kindreds a and b (fig 3 ). 

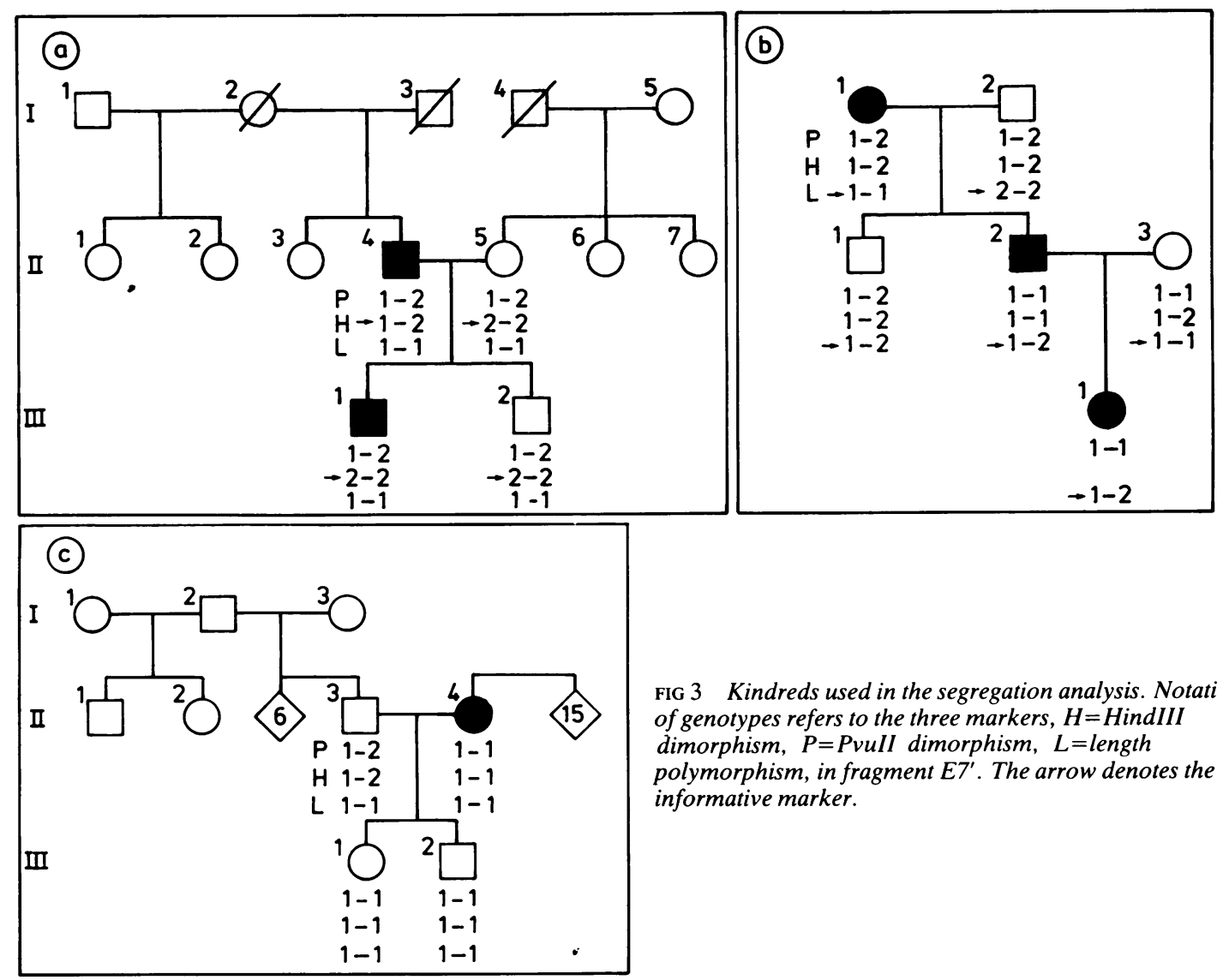

FIG 3 Kindreds used in the segregation analysis. Notation of genotypes refers to the three markers, $H=H$ indIII dimorphism, $P=P$ vull dimorphism, $L=$ length polymorphism, in fragment E7'. The arrow denotes the informative marker.

KINDRED a

II.4 is heterozygous for the $\mathrm{H}$ marker. Paternal allele 2 has been inherited by both children though the achondroplasia gene has only been passed to one (III.1).

KINDRED b

II. 2 is heterozygous for the variable length marker $\mathrm{L}$. The phase is known because allele 2 was inherited from the unaffected father I.2. This normal paternal allele has been passed on to III.1 who has also inherited the achondroplasia gene from her father.

\section{KINDRED c}

The affected parent (II.4) is homozygous for all three markers so the segregation of COL2A1 among generation III could not be studied.

PATERNITY

Fig 4 shows the $\overline{H i n f I}$ fragments cross hybridising with the minisatellite probe in pedigree a. All fragments present in generation III were inherited from generation II. This effectively confirms the relationship between these subjects. Similar confirmation was obtained for pedigree $b$ (not shown).

\section{Discussion}

Contrary to reports implicating gross structural changes in the gene encoding type II collagen (COL2A1) as the basic defect in achondroplasia, we were unable to demonstrate any such abnormalities in the structure of this gene in 19 patients with typical achondroplasia. Deletion of the entire gene was definitely excluded in 14 of these patients. Further, we were able to demonstrate in two kindreds that COL2A1 segregates independently from the achondroplasia locus and cannot, therefore, contain the causal mutation. Erroneous exclusion because of non-paternity was eliminated by 


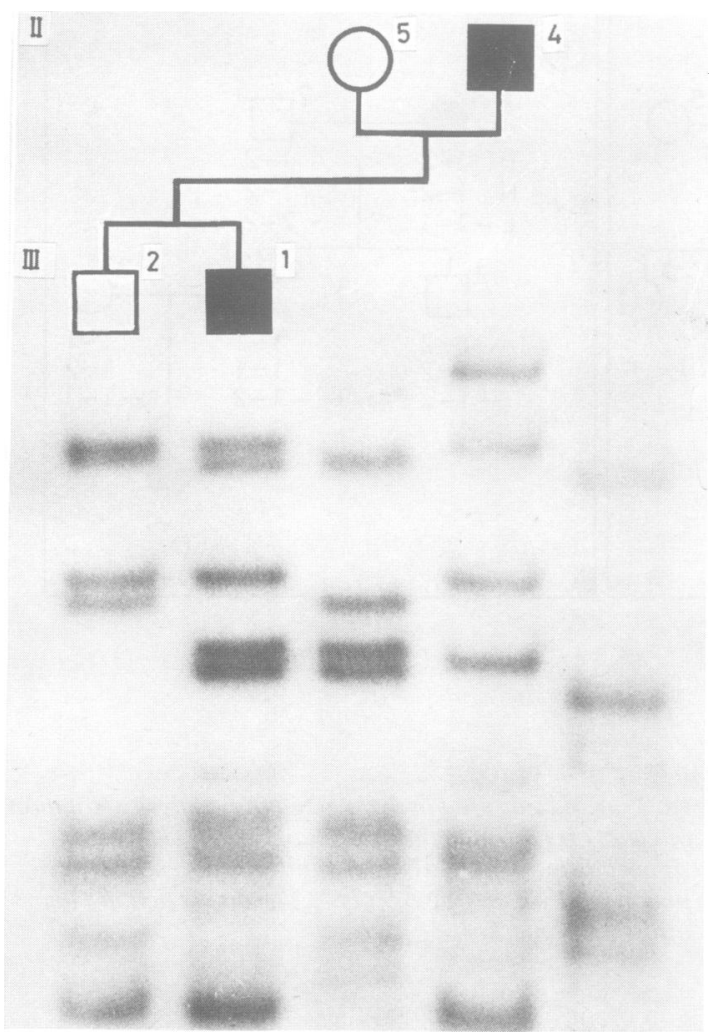

FIG 4 Confirmation of relationships in a kindred using Hinfl digests probed with minisatellite 15.1.11.4. The autoradiograph shows fragments between 2.5 and $6.0 \mathrm{~kb}$. The unlabelled track is from an unrelated subject.

hybridisation of 'minisatellite' sequences. This will clearly become a routine procedure in any comparable linkage analysis. Although heterogeneity can never be ruled out, if the clinical homogeneity of achondroplasia were a reflection of mutation at a single locus then these findings can be taken to exclude COL2A1 as that locus in most if not all cases. We offer no explanation of the conflicting results reported by Strom et al. ${ }^{10} 11$

The major benefit to be derived from these results is to direct effort away from investigations of type II collagen in the search for the basic defect in achondroplasia.

We thank the many colleagues, in particular the members of the Skeletal Dysplasia Group, who have referred patients to us for this study. Clone 15.1.11.4 was a generous gift from Dr Alec Jeffreys. We have appreciated the advice and encouragement of Drs Roger Smith, Ruth Wynne-Davies, and Marcus Pembrey. This work was supported in part by grants from the Nuffield Foundation (DJO), Arthritis and Rheumatism Council (BPW), Wellcome Trust (ET), and from the Rehabilitation and Medical Research Trust.

\section{References}

1 Gardner RJM. A new estimate of the achondroplasia mutation rate. Clin Genet 1977;11:31-8.

2 Penrose LS. Parental age and mutation. Lancet 1955;ii:312.

${ }^{3}$ Bodmer WF. Cavalli-Sforza LL. Genetics, evolution and man. San Francisco: Freeman, 1976;287-94.

4 Rimoin DL, Hughes GN, Kaufman RL, Rosenthal RE, McAllister WH, Silberberg R. Endochondral ossification in achondroplastic dwarfism. N Engl J Med 1970;83:728-35.

${ }^{5}$ Rosenfeld RG, Hintz RL. Normal somatomedin and somatomedin receptor in achondroplastic dwarfism. Horm Metab Res 1980;12:76-9.

${ }^{6}$ Solomon E, Hiorns LR, Cheeh KSE, et al. Assignment of the gene encoding human type II collagen (COL2A1) to chromosome 12. Cytogenet Cell Genet 1984;37:588-9.

7 Stanescu V, Maroteaux P, Stanescu R. Etude par electrophorese sur gel des chaines $\alpha$ et des $\mathrm{CNBr}$ peptides du collagene du cartilage de croissance dans les chondrodysplasies. Ann Genet (Paris) 1975;19:119-25.

' Svejcar J. Biochemical analysis of epiphyseal cartilage during growth and in some chondrodysplasias. Birth Defects 1975:11:227-30.

" Hollister DW, Byers PH, Holbrook KA. Genetic disorders of collagen metabolism. Adv Hum Genet 1982:12:1-87.

11) Strom CM. Achondroplasia due to DNA insertion into the type II collagen gene. Pediatr Res 1984:18:226A

"Strom CM, Eng CEL, Christides T, Belles C, Pauli R. Detection of gene deletions in the human type II procollagen gene in 8 patients with achondroplasia using gene dosage analysis. Pediatr Res 1985:19:254A.

12 Sykes BC. A high frequency Hind III restriction site polymorphism within a collagen gene. Disease Markers 1983;1:141-6.

${ }^{13}$ Sykes B, Smith R, Vipond S, Paterson C, Cheah K, Solomon E. Exclusion of the $\alpha 1$ (II) cartilage collagen gene as the mutant locus in type IA osteogenesis imperfecta. J Med Genet 1985;22:187-91

${ }^{14}$ Sykes BC, Ogilvie DJ. Lethal osteogenesis imperfecta and a collagen gene deletion. $\mathrm{Br}$ Med J 1984;288:1380-1.

15 Sykes BC, Ogilvie DJ, Wordsworth BP. Lethal osteogenesis imperfecta and a collagen gene deletion. Length polymorphism provides an alternative explanation. Hum Genet 1985:70:35-7.

16 Jeffreys AJ, Wilson V, Thein SL. Hypervariable 'minisatellite' regions in human DNA. Nature 1985;314:67-73.

17 Weiss EH, Cheah KSE, Grosveld FG, et al. Isolation and characterisation of a human collagen $\alpha 1$ (I)-like gene from a cosmid library. Nucleic Acids Res 1982;10:1981-94.

18 Cheah KSE, Stoker NG, Griffin JR, et al. Identification and characterisation of the human $\alpha 1$ (II) collagen gene (COL2A1). Proc Natl Acad Sci USA 1985;82:2555-9.

Correspondence and requests for reprints to $\mathrm{Dr} B$ Sykes, Nuffield Department of Pathology, John Radcliffe Hospital, Headington, Oxford OX3 9DU. 